University of South Carolina

Scholar Commons

9-6-2007

\title{
Inclusion of Electrochemically Active Guests by Novel Oxacalixarene Hosts
}

\author{
Daniel Sobransingh \\ University of South Carolina - Columbia \\ Mahender B. Dewal \\ University of South Carolina - Columbia \\ Jacob Hiller \\ University of South Carolina - Columbia \\ Mark D. Smith \\ University of South Carolina - Columbia, mdsmith3@mailbox.sc.edu \\ Linda S. Shimizu \\ University of South Carolina - Columbia, shimizul@mail.chem.sc.edu
}

Follow this and additional works at: https://scholarcommons.sc.edu/chem_facpub

Part of the Chemistry Commons

\section{Publication Info \\ Published in New Journal of Chemistry, Volume 32, Issue 1, 2007, pages 24-27. \\ (C) New Journal of Chemistry 2008, Royal Society of Chemistry.}

This Article is brought to you by the Chemistry and Biochemistry, Department of at Scholar Commons. It has been accepted for inclusion in Faculty Publications by an authorized administrator of Scholar Commons. For more information, please contact digres@mailbox.sc.edu. 


\title{
Inclusion of electrochemically active guests by novel oxacalixarene hosts $\nmid$
}

\author{
David Sobransingh, Mahender B. Dewal, Jacob Hiller, Mark D. Smith and \\ Linda S. Shimizu*
}

Received (in Durham, UK) 3rd July 2007, Accepted 30th August 2007

First published as an Advance Article on the web 6th September 2007

DOI: $10.1039 /$ b709806e

We demonstrate for the first time the utility of oxacalixarenes as hosts and investigate the forces that influence the thermodynamics of binding.

\section{Introduction}

Calixarenes are useful host molecules in supramolecular systems and have a wide range of industrial applications such as metal sequestration and waste remediation. ${ }^{1}$ Classical calixarenes employ carbon atoms to bridge their aromatic moieties; however, the incorporation of non-carbon bridging atoms within the calixarene framework is an interesting yet underutilized method of increasing structural diversity and conferring new chemical and physical properties upon this class of molecule. $^{2}$ The calixarene skeleton has been modified with heteroatoms including sulfur ${ }^{3}$ and nitrogen, ${ }^{4}$ but incorporation of bridging oxygen atoms has been scarce. ${ }^{5}$

Oxygen bridged calixarenes (oxacalixarenes) first appeared in the literature in $1966^{5}$ but only a handful of papers were published on them prior to 2005. Recent advances by Katz et $a .^{6}$ has led to a doubling of the number of published papers $^{6,7}$ on the synthesis and structure of oxacalixarenes. The exploration of the host properties of oxacalixarenes however, has been conspicuously absent from the literature. In this paper we probe the utility of oxacalixarenes as hosts using the electrochemically active guest molecules ferrocene and cobaltocenium. We report the synthesis of two new oxacalixarene based hosts $(\mathbf{2}, \mathbf{3})$ (Fig. 1) and demonstrate for the first time that oxacalixarenes $(\mathbf{1}, \mathbf{3})$ show host-guest interactions with the ferrocene $(\mathbf{F}) /$ ferrocenium $\left(\mathbf{F}^{+}\right)$and cobaltocenium $\left(\mathbf{C}^{+}\right)$/cobaltocene $(\mathbf{C})$ redox couples. Both host $\mathbf{1}$ and $\mathbf{3}$ show a significant thermodynamic preference for positively charged guests over the neutral species and display an unusually large negative shift of the half-wave potential $\left(E_{1 / 2}\right)$ in voltammetric experiments.

\section{Results and discussion}

Functionalized oxacalix[4]arenes such as 1, adopt a 1,3-alternate or saddle conformation in which the hydroxyl substituted rings are nearly parallel. ${ }^{6}$ Oxacalixarene $\mathbf{1}$ has the unique characteristic of having two electron-rich aromatic rings by virtue of the electron donating hydroxyl substituents alternat-

Department of Chemistry and Biochemistry, University of South Carolina, 631 Sumter St. Columbia, SC 29208, USA.

E-mail: shimizul@mail.chem.sc.edu; Fax: +1 803777 9521;

Tel: +18037772066

$\dagger$ Electronic supplementary information (ESI) available: Synthesis and characterization of hosts, estimation of binding constants, and X-ray structures of hosts 2 and 3. See DOI: 10.1039/b709806e ing with two electron deficient nitro substituted aromatic rings. Analysis of the geometry and electrostatic surface potential (Fig. 2) of 1 reveals that the two hydroxyl substituted aromatics in the saddle conformation are capable of including complementary guest species by non-covalent interactions. The steric requirements of $\mathbf{F}$ and $\mathbf{C}^{+}$on the energy minimized structure were investigated using space filling models.

We investigated the guest binding properties of $\mathbf{1}$ in solution by ${ }^{1} \mathrm{H}$ NMR spectroscopy between $\mathbf{1}$ and neutral $\mathbf{F}$ in a wide range of polar and non-polar solvents including $\mathrm{CD}_{2} \mathrm{Cl}_{2}$, however solubility issues hampered these experiments and no interactions could be observed. In contrast, cyclic voltammetric experiments in $\mathrm{CH}_{2} \mathrm{Cl}_{2}$ showed a shift of the $E_{1 / 2}$ associated with the one-electron oxidation of $\mathbf{F}$ to less positive values by $-114 \mathrm{mV}$ in the presence of 8 equiv. of host 1 (Fig. 3). This reveals that the host has a significant thermodynamic preference for the positively charged $\mathbf{F}^{+}$over the neutral species and is strong evidence of complexation between the electrochemically generated $\mathbf{F}^{+}$and $\mathbf{1}$. This negative shift corresponds to a 85 fold enhancement of binding upon electrochemical generation of the positive charge as calculated from eqn (1). ${ }^{8}$ The negative shift was quantified as a $2.6 \mathrm{kcal}$ $\mathrm{mol}^{-1}$ increase in stability of the complex in going from $\mathbf{F}$ to $\mathbf{F}^{+}$. The recorded voltammograms also showed some quasireversibility upon host addition. This is an expected consequence of complexation as the electrode has less access to $\mathbf{F} / \mathbf{F}^{+}$and electron transfer takes place at a greater average distance than when uncomplexed.

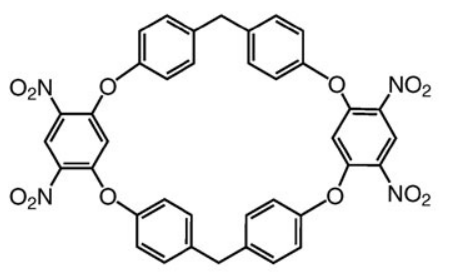

3

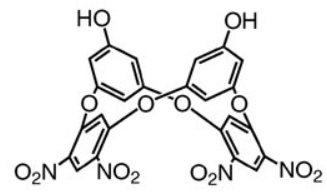

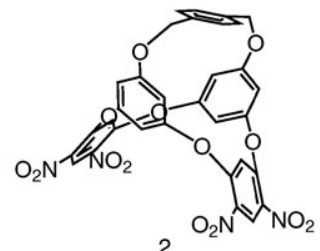

2

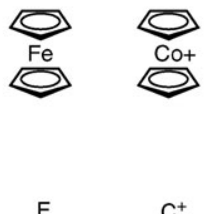

$\mathrm{C}^{+}$
Fig. 1 Structures of hosts $(\mathbf{1}, \mathbf{2}, \mathbf{3})$ and guests $\left(\mathbf{F}, \mathbf{C}^{+}\right)$. 


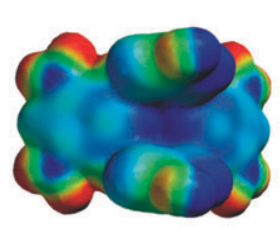

1

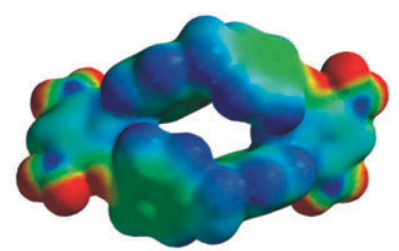

3
35

$-45$

Fig. 2 Electrostatic surface potential of hosts $\mathbf{1}$ and $\mathbf{3}$ after energy minimization in a PM3 force field using Spartan.

$$
K_{\text {red }} / K_{\text {ox }}=\exp \left(n F \Delta E_{1 / 2} / R T\right)
$$

In analogy to the supramolecular electrochemistry reported by Gupta and Linschitz, ${ }^{9 a}$ as well as others, ${ }^{9 b, c}$ the association constant $\left(K_{\mathrm{ox}}\right)$ for the $\mathbf{1} \cdot \mathbf{F}^{+}$complex was estimated using eqn (2) (under high concentrations of host and assuming $K[\mathrm{H}] \gg 1$ ), where $[\mathrm{H}]$ is the host concentration, $E_{1 / 2}$ is the half wave potential $\mathbf{F} / \mathbf{F}^{+}$in the presence of host, and $E_{1 / 2}{ }^{0}$ is the half wave potential of the free $\mathbf{F} / \mathbf{F}^{+}$redox couple.

$$
E_{1 / 2(\text { complex })}=E_{1 / 2}^{0} \text { (free) }+(R T / F) \ln \left(1+K_{\text {ox }}[\mathrm{H}]\right)
$$

The association contant $\left(K_{\mathrm{ox}}\right)$ for the $\mathbf{1} \cdot \mathbf{F}^{+}$complex was estimated as $7400 \mathrm{M}^{-1}$. As previously stated, this association was 85 times stronger than for the neutral $\mathbf{1} \cdot \mathbf{F}$ complex and yields an association constant $\left(K_{\text {red }}\right)$ of $87 \mathrm{M}^{-1}$ for $\mathbf{1} \cdot \mathbf{F}$. PGSE NMR diffusion coefficients verify the absence of larger assemblies in solution and suggest that these complexes have $1: 1$ stoichiometry. ${ }^{10}$ A large body of work serves to document that a characteristic feature of calixarene hosts is their $\pi$-coordination to cationic guests. ${ }^{11}$ The driving force for the $\mathbf{1} \cdot \mathbf{F}^{+}$ complexation is likely cation $-\pi$ interactions between the positively charged $\mathbf{F}^{+}$and the $\pi$-electrons of the hydroxyl substituted rings of $\mathbf{1}$. Molecular modeling experiments coupled with the conformation of $\mathbf{1}$ in the crystal state suggests a 'chopstick type' $\pi$-coordination of host to cationic guest. ${ }^{12}$ Attempts to reduce the nitro groups of $\mathbf{1}$ to amines to yield a

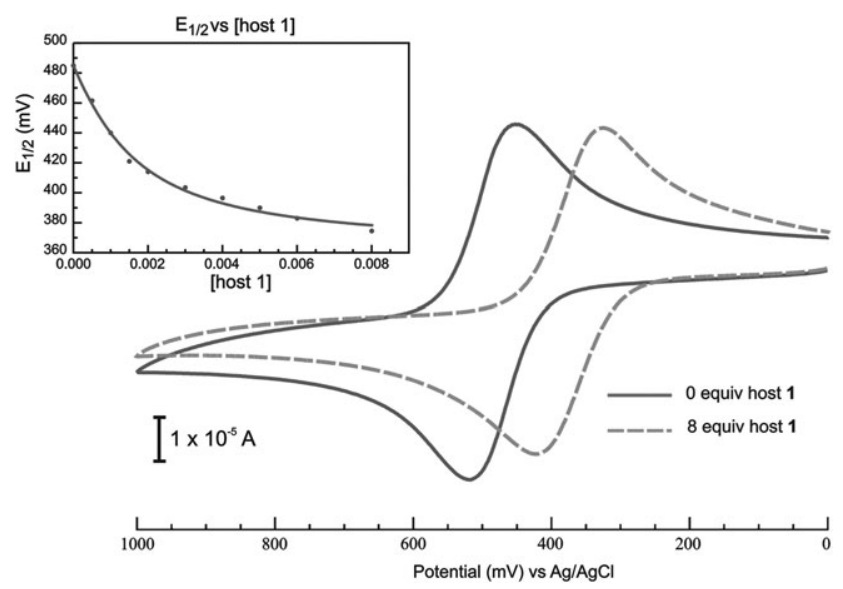

Fig. 3 Cyclic voltammetric response on a glassy carbon electrode $\left(0.071 \mathrm{~cm}^{2}\right)$ of $\mathbf{F}(1.0 \mathrm{mM})$ in $\mathrm{CH}_{2} \mathrm{Cl}_{2}$ in the absence (solid line) and in the presence of 8 equiv. host $\mathbf{1}$ (broken line) at a scan rate of $0.1 \mathrm{~V} \mathrm{~s}^{-1}$ with $0.1 \mathrm{M}$ tetrabutylammonium hexafluorophosphate supporting electrolyte. Inset shows shifting of $E_{1 / 2}$ as a function of host concentration. more electron-rich oxacalixarene resulted in degradation because the more electron-rich oxacalixarene is very unstable and susceptible to oxidation and radical formation.

In order to verify that the chopsticks formed by the hydroxyl substituted electron dense aromatic rings of $\mathbf{1}$ is the binding site we synthesized the control host molecule $\mathbf{2}$ which contains a $p$-xylene group bridging the two hydroxyls. The X-ray crystal structure of $\mathbf{2}$, obtained by vapor diffusion of hexane into an ethyl acetate solution, has crystallographically imposed mirror symmetry. The proposed binding site is blocked, hindering the approach of any guest. In sharp contrast to electrochemistry of $\mathbf{F}$ in the presence of host $\mathbf{1}$, the cyclic voltammetric experiments of $\mathbf{F}$ with host $\mathbf{2}$ showed no shifting of the $E_{1 / 2}$ associated with the one-electron oxidation of $\mathbf{F}$. This observation is consistent with no complexation between host $\mathbf{2}$ and $\mathbf{F}$ provides further evidence that the 1,3-alternating electron-rich rings of $\mathbf{1}$ are involved in complexation.

${ }^{1} \mathrm{H}$ NMR experiments with $\mathbf{C}^{+}$were performed and upon addition of cobaltocenium hexafluorophosphate to a $\mathrm{CD}_{2} \mathrm{Cl}_{2}$ solution of $\mathbf{1}$ a upfield shift of the proton resonance corresponding to the protons para to the hydroxyl groups on $\mathbf{1}$ was observed. This observation is in agreement with the formation of a complex between these two species and shows that the hydroxyl substituted rings are involved in complexation. As with $\mathbf{F}^{+}$, the interaction between $\mathbf{1}$ and $\mathbf{C}^{+}$is driven by chopstick type $\pi$-coordination of host to cationic guest. Control experiments using quaternary ammonium salts produced a similar shift of the host proton resonances supporting the hypothesis that cation $-\pi$ interactions drive the complexation. ${ }^{1} \mathrm{H}$ NMR experiments with control host $\mathbf{2}$ with both $\mathbf{F}$ and $\mathbf{C}^{+}$ guests also showed no complexation induced shifting of any proton resonances demonstrating that control host $\mathbf{2}$ has very little interaction with these guests.

The electron deficient dinitro substituted rings of $\mathbf{1}$ can be reduced in cyclic voltammetric experiments. The reduction of 1 however, has slow electrochemical kinetics and also caused precipitation on the electrode surface which results in distortion of the voltammetric waves. These distortions mask the voltammetric response of $\mathbf{C}^{+}$at higher concentrations and prevented binding saturation from being observed in cyclic voltammetric experiments. Despite these complications, the $E_{1 / 2}$ associated with the one-electron reduction of $\mathbf{C}^{+}$was observable at lower concentrations of $\mathbf{1}$ which underwent a shift to less positive values upon addition of $\mathbf{1}$ (ESI $\dagger$ ). This is also evidence that $\mathbf{1}$ prefers the positively charged $\mathbf{C}^{+}$over the reduced neutral species and strengthens the contention that cation $-\pi$ interactions drive this complexation. Voltammetric experiments showed no shifts of the $E_{1 / 2}$ associated with the one-electron reduction of $\mathbf{C}^{+}$when host $\mathbf{2}$ was added. This observation consistent with no complexation between these species, which is expected as host $\mathbf{2}$ has xylene blocking the proposed binding site.

Building upon these observations we synthesized the new macrocycle $\mathbf{3}$, that has an oxacalixarene framework with a larger cavity for guest inclusion. 3 was synthesized by reaction of bis(4-hydroxyphenyl)methane with 1,5-difluoro-2,4-dinitrobenzene using $\mathrm{K}_{2} \mathrm{CO}_{3}$ as the base in DMSO (ESI $\dagger$ ). Crystals were obtained by vapor diffusion of hexane into an ethyl acetate solution of $\mathbf{3}$. The crystal structure of 3 (Fig. 4) reveals 


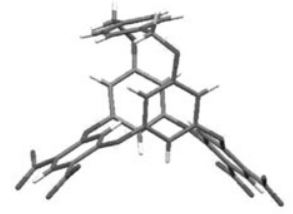

2
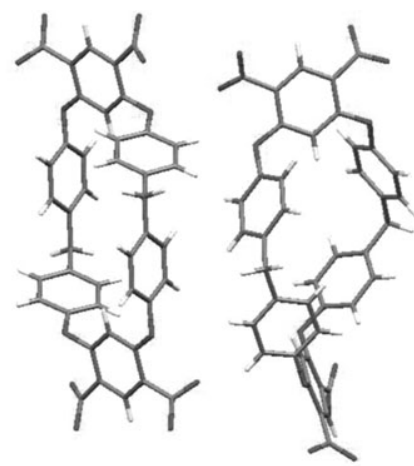

3
Fig. 4 Crystal structures ${ }^{13}$ of novel hosts $\mathbf{2}$ and $\mathbf{3}$ (showing two conformations for host $\mathbf{3}$ ).

two crystallographically independent molecules, one located on a position of general symmetry and the other situated about an inversion center. Both conformations display a sizeable cavity filled with disordered solvent molecules. Although these conformations differ from host $\mathbf{1}$, analysis of the electrostatic surface potential (Fig. 2) reveals that they also have an electron-rich inner cavity formed by four aromatic rings which can bind cationic guests.

${ }^{1} \mathrm{H}$ NMR experiments showed complexation induced downfield shifting and broadening of the $\mathbf{F}$ proton resonances (Fig. 5) upon addition of host 3 in $\mathrm{CD}_{2} \mathrm{Cl}_{2}$. Voltammetric experiments show that host 3 itself can also undergo electrochemical reduction of the electron deficient nitro substituted rings. Upon complexation with $\mathbf{F}$ the reduction of host $\mathbf{3}$ underwent a shift of $-22.5 \mathrm{mV}$ indicating that the electronpoor rings of the host are afforded thermodynamic stability by interaction with the more electron-rich $\mathbf{F}$. This electrochemical evidence suggests that the driving force of this interaction is electrostatic in nature between the electron-rich $\mathbf{F}$ and the electron deficient nitro substituted rings of 3 .

The $E_{1 / 2}$ associated with the one-electron oxidation of ferrocene was also influenced by host 3 . Voltammetric experiments showed that this $E_{1 / 2}$ was shifted to less positive values by $-27 \mathrm{mV}$ upon addition of 8 equiv. of host 3 . Despite observed complexation with neutral $\mathbf{F}$, this host cavity displays

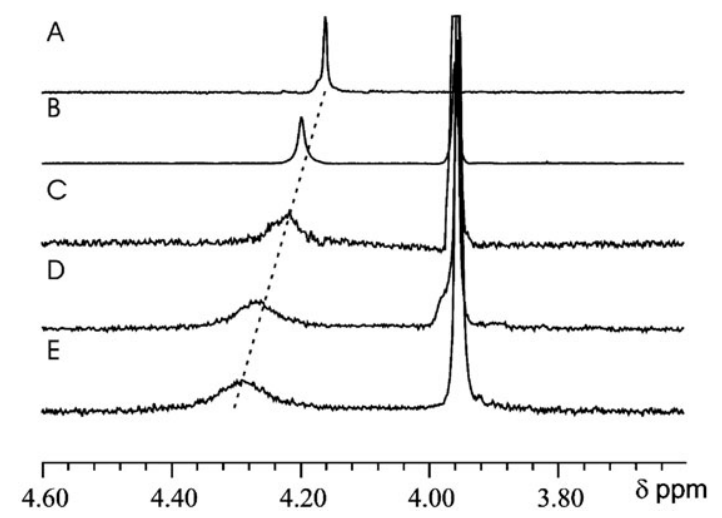

Fig. $5{ }^{1} \mathrm{H}$ NMR (300 MHz) spectra of $\mathbf{F}$ in $\mathrm{CD}_{2} \mathrm{Cl}_{2}$, in the presence of (A) 0 equiv., (B) 3 equiv., (C) 4 equiv., (D) 5 equiv. and (E) 6 equiv. of 3. Complexation induced broadening and downfield shifting of $\mathbf{F}$ proton resonances are observed as more host is added. a thermodynamic preference for the positively charged $\mathbf{F}^{+}$as cation $-\pi$ interactions would be possible with the oxidized guest which would be stronger than any electrostatic attraction in the $\mathbf{3} \cdot \mathbf{F}$ complex. The $E_{1 / 2}$ shift reflects a 2.9 fold increase of the association constant upon electrochemical oxidation of $\mathbf{F}$ to the cationic $\mathbf{F}^{+}$and corresponds to a $0.6 \mathrm{kcal} \mathrm{mol}^{-1}$ increase in stability from the $\mathbf{3} \cdot \mathbf{F}$ to the $\mathbf{3} \cdot \mathbf{F}^{+}$complex. We estimated the association constants to be $107 \mathbf{M}^{-1}$ for the $\mathbf{3} \cdot \mathbf{F}$ complex and $310 \mathbf{M}^{-1}$ for the $\mathbf{3} \cdot \mathbf{F}$ complex. When the $\mathbf{3} \cdot \mathbf{F}^{+}$association constant is contrasted to the association constant for the $\mathbf{1} \cdot \mathbf{F}^{+}$complex, it becomes evident that $\mathbf{1}$ is capable of stronger cation $-\pi$ interactions. This is probably due to the higher electron density (Fig. 2) of the hydroxyl substituted saddle of $\mathbf{1}$ compared to the unsubstituted rings of $\mathbf{3}$.

${ }^{1} \mathrm{H}$ NMR experiments also confirmed that $\mathbf{3}$ formed a complex with $\mathbf{C}^{+}$which was observed by a small upfield shift of the $\mathbf{C}^{+}$proton resonances. The exchange was slow in the NMR timescale as observed by two sets of proton resonances, for complexed and uncomplexed $\mathbf{C}^{+}$, with the complexed proton resonances growing at the expense of the uncomplexed until binding saturation. The driving force for this complexation is cation $-\pi$ interactions. Host $\mathbf{3}$ displays a reduction wave very close to that of $\mathbf{C}^{+}$, which made voltammetric experiments difficult, however, a negative shift of the $E_{1 / 2}$ associated with the one-electron reduction of $\mathbf{C}^{+}$was observed, a phenomenon consistent with cation $-\pi$ interactions.

\section{Conclusion}

Overall, this work sets a precedent for oxacalixarene binding and demonstrates that oxacalixarenes can function as effective hosts by using ferrocene (F) and cobaltocenium $\left(\mathbf{C}^{+}\right)$and their redox partners as guests. Although the association constants reported herein are modest, this study is relevant and necessary for advancing the field of oxacalixarenes. Electrochemical and other data suggest that the strongest complexes are formed with cationic guests and as this affords the opportunity for cation $-\pi$ interactions which is typical and characteristic of classical calixarene hosts. More elaborate molecular designs involving electron donating groups are being investigated to improve binding characteristics.

\section{Acknowledgements}

We would like to thank the NSF (CHE-071817), the Petroleum Research Fund and the University of South Carolina, Office of Research and Health Sciences for financial support of this work.

\section{References}

1 (a) C. D. Gutsche, Calixarenes Revisited, Royal Society of Chemistry, Cambridge, 2000; (b) V. Böhmer, Angew. Chem., Int. Ed. Engl., 1995, 34, 713.

2 B. König and M. H. Fonseca, Eur. J. Inorg. Chem., 2000, 2303.

3 (a) H. Kumagai, M. Hasegawa, S. Miyanari, Y. Sugawa, Y. Sato, T. Hori, S. Ueda, H. Kamiyama and S. Miyano, Tetrahedron Lett., 1997, 38, 3971; (b) N. Kon, N. Iki and S. Miyano, Tetrahedron Lett., 2002, 43, 2231; (c) P. Lhotak, Eur. J. Org. Chem., 2004, 1675. 
4 (a) A. Ito, Y. Ono and K. Tanaka, J. Org. Chem., 1999, 64, 8236; (b) T. D. Selby and S. C. Blackstock, Org. Lett., 1999, 1, 2053; (c) M.-X. Wang, X.-H. Zhang and Q.-Y. Zheng, Angew. Chem., Int. $E d$., 2004, 43, 838; (d) Y. Suzuki, T. Yanagi, T. Kanbara and T. Yamamoto, Synlett, 2005, 263; (e) H. Tsue, K. Ishibashi, H. Takahashi and R. Tamura, Org. Lett., 2005, 7, 2165.

5 (a) N. Sommer and H. A. Staab, Tetrahedron Lett., 1966, 25, 2837; (b) F. P. A. Lehmann, Tetrahedron, 1974, 30, 727; (c) E. E. Gilbert, J. Heterocycl. Chem., 1974, 11, 899; (d) F. Bottino, S. Foti and S. Papalardo, Tetrahedron, 1976, 32, 2567; (e) X. Li, T. G. Upton, C. L. D. Gibb and B. C. Gibb, J. Am. Chem. Soc., 2003, 125, 650.

6 (a) J. L. Katz, M. B. Feldman and R. R. Conry, Org. Lett., 2005, 7, 91; (b) J. L. Katz, K. J. Selby and R. R. Conry, Org. Lett., 2005, 7, 3505; (c) J. L. Katz, B. J. Geller and R. R. Conry, Org. Lett., 2006, 8, 2755; (d) J. L. Katz, B. J. Geller and P. D. Foster, Chem. Commun., 2007, 1026.

7 (a) W. Maes, W. Van Rossum, K. Van Hecke, L. Van Meervelt and W. Dehaen, Org. Lett., 2006, 8, 4161; (b) C. Zhang and C. -F. Chen, J. Org. Chem., 2007, 72, 3880; (c) F. Yang, L. Yan, K. Ma, L. Yang, J. Li, L. Chen and J. You, Eur. J. Org. Chem., 2006, 12, 1109 .

8 (a) A. E. Kaifer and M. Gómez-Kaifer, Supramolecular Electrochemistry, Wiley-VCH, Weinheim, Germany, 2000; (b) C. Bourgel, A. S. F. Boyd, G. Cooke, H. A. de Cremiers, F. M. A. Duclairoir and V. M. Rotello, Chem. Commun., 2001, 1954.

9 (a) N. Gupta and H. Linschitz, J. Am. Chem. Soc., 1997, 119, 6384; (b) J. -M. Savéant, J. Phys. Chem. B, 2001, 105, 8995; (c) M.
Gómez, C. Z. Gómez-Castro, I. I. Padilla-Martínez, F. J. Martínez-Martínez and F. J. González, J. Electroanal. Chem., 2004, 567, 269.

10 L. Avram and Y. Cohen, J. Am. Chem. Soc., 2002, 124, 15148.

11 (a) A. B. Rozhenko, W. W. Schoeller, M. C. Letzel, B. Decker, C. Agena and J. Mattay, Chem.-Eur. J., 2006, 12, 8995; (b) S. Ishihara and S. Takeoka, Tetrahedron Lett., 2005, 47, 181; (c) H. Konishi, K. Takahashi, N. Nakamura, H. Sakamoto and K. Kimura, J. Inclusion Phenom. Macrocycl. Chem., 2006, 54, 147; (d) R. Arnecke, V. Böhmer, R. Cacciapaglia, A. D. Cort and L. Mandolini, Tetrahedron, 1997, 53, 4901; (e) D. A. Dougherty, Science, 1996, 271, 163.

12 J. Y. Lee, J. Kwon, C. S. Park, J.-E. Lee, W. Sim, J. S. Kim, J. Seo, I. Yoon, J. H. Jung and S. S. Lee, Org. Lett., 2007, 9, 493.

13 Crystallography: 2: $\mathrm{C}_{32} \mathrm{H}_{18} \mathrm{~N}_{4} \mathrm{O}_{14}, M=682.50$, monoclinic, space group $P 2_{1} / m, a=8.8759(8), b=12.7053(12), c=16.6618(15) \AA$, $\beta=103.925(2)^{\circ}, V=1823.7(3) \AA^{3}, Z=2, T=150 \mathrm{~K}, 2533$ reflections, 1861 with $I>2 \sigma(I) ; R($ all $)=0.0648, R(I>2 \sigma(I))=$ $0.0480, w R$ (all) $=0.1269, w R(I>2 \sigma(I))=0.1206$. 3: $\mathrm{C}_{38} \mathrm{H}_{24} \mathrm{~N}_{4} \mathrm{O}_{12}, M=728.61$, triclinic, space group $P \overline{1}, a=$ 12.1115(4), $b=14.0678(4), c=17.4915(5) \AA, \alpha=79.9180(10)$, $\beta=86.4530(10), \gamma=74.7700(10)^{\circ}, V=2830.77(15) \AA^{3}, Z=3, T$ $=150 \mathrm{~K}, 10008$ reflections, 7259 with $I>2 \sigma(I) ; R($ all $)=0.0530$, $R(I>2 \sigma(I))=0.0377, w R($ all $)=0.0827, w R(I>2 \sigma(I))=$ 0.07820 . CCDC reference numbers 659154 (2) and 659155 (3). For crystallographic data in CIF or other electronic format see DOI: $10.1039 /$ b709806e. 